\title{
FLT3 Tyrosine Kinase Domain Point Mutation
}

National Cancer Institute

\section{Source}

National Cancer Institute. FLT3 Tyrosine Kinase Domain Point Mutation. NCI Thesaurus.

Code C67495.

Single nucleotide mutations in the tyrosine kinase domain encoded by the human FLT3 gene that are associated with acute myeloid leukemia and poor prognosis. 